\title{
Por que não Combinar a Classificação de Cargos Com a Organização de Serviços?
}

\author{
Clyde E. Shoe \\ Do grupo de classificação de cargos da \\ 11' Região do Serviço Civil dos \\ Estados Unidos \\ Tradução de MarY CARDoso
}

\begin{abstract}
A
CRFDITA a maioria dos administradores que a melhor maneira pela qual pode desempenhar as tarefas que lhe são confiadas consiste em dividi-las em especialidades, como orçamento e pessoal, e subdividir pessoal em diferentes áreas, tais como enquadramento e relações de trabalho, esta última por sua vez subdividida em orientação e administração - e assim por diante, numa dúzia de outras especialidades. Esperam êles conseguir maiores vantagens, com a mais profunda penetração que tal subdivisão torna possivel, do que desvantagens, que resultariam do perigo de ver as coisas pela rama e do esfôrço extra de coordenação exigido para que se obtivesse uma unidade de propósito.

Mas, por que correr o risco, quando não é necessário? Querome referir a duas subdivisões no campo da administração federal, derominadas classificação de cargos e organização e exame de niétodos.

O objetivo dêste estudo é sugerir que tais propósitos se combinem num esquema único, mostrando as possiveis vantagens que ciecorrerão de semelhante organização de trabalho. Isso não irá, exatamente, ampliar as fronteiras do conhecimento em matéria de administração. Já foi sugerido anteriormente mas, pelo que sei, precisa ainda ter a oportunidade de uma séria tentativa, especialmente em serviços regionais, onde não é prático adotar a especialização.
\end{abstract}

A principal justificativa para a especialização, em administração ou eni qualquer outro campo, é que o assunto é muito amplo 
para que uma pessoa o possa conhecer competentemente, ou que os segmentos são tão dissemelhantes que não se podem misturar. No estudo da classificação de cargos e da organização e exame de métodos, nada me impressionou mais do que a similaridade entre aquilo que os praticantes de ambas as técnicas devem saber, em niatéria de princípios, entre os passos que devem dar, para coleta de dados, entre as decisões afins, que precisarão tomar.

Uma das maiores vantagens da combinação das funções de organização e métodos com as de classificação, num conceito único, consiste na possibilidade de economia de trabalho, já que, em ambas as especialidades, uma das fases mais importantes é a demorada tarefa da pesquisa. Êsse estágio assume grandes proporções ern qualquer estudo ou investigação e os fatos, que cada especialista precisa conhecer, são de um modo geral os mesmos.

Assim, por exemplo, para uma sã apreciação em qualque: das duas especialidades é preciso que o técnico tenha conhecimento do propósito ou missão da organização e dos tipos de pessoas necessárias para atingi-los; do tipo e da fonte de informação essencial de onde deriva sua atividade; de suas linhas de comunicação, autoridade e promoção. A acumulação de conhecimento sôbre tais fatos nem sempre é fácil, e o processo é, freqüentemente, bastante lento.

Sendo assim, nossos dois especialistas gastam muito de seu tempo palmilhando o mesmo terreno, fazendo as mesmas per guntas e aprendendo as mesmas coisas sôbre relações de trabalino entre pessoas. Êsse processo de coleta de dados, é claro, nâo constitui tarefa de $u \mathrm{~m}$ momento, mas prossegue continuamente, conforme o exijam os acontecimentos, as personalidades, as condições do ambiente. Não há dúvida de que, se um só indivíduo fôr examinar as unidades de trabalho sob o duplo aspecto da organização e da classificação, não realizará trabalho tão extenso quanto 5 que seria feito por dois pesquisadores, cada um confinado apenas à sua própria especialidade. Não será, porém, pouco razoável admitir que um técnico, que combine conhecimento dos dois setores, possa cobrir bem mais da metade do mesmo terreno, realizando, assim, significativa economia.

Tem sido afirmado que, embora os examinadores de métodos e de organização e os classificadores de cargos recolham os mesmos fatos, os encaram de diferentes pontos-de-vista, com a inente imbuida de diferentes principios e em atitudes orientadas para diferentes objetivos. E que, sendo assim, os fatos de um não têm valor para o outro - mais ou menos como seria se um pintor transmitisse a um geólogo suas observações sôbre uma montanha. 
Se existe diferença em perspectiva, principio e objetivo, então essa diferença tem muito pouca importância para a aliança que sugerinos. Comparemos, para exemplificar, alguns dos princípios, regras ou como se prefira chamar, mùtuamente compativeis:

Continuidade - as estruturas organizacionais deveriam estabelecer escalas de promoção, de modo que se grupem os deveres e estabeleçam os cargos numa tal relação que permita a seus ocupantes a aquisição da experiência necessária ao preenchimento de cargos correlacionados de maior responsabilidade. Pouros - se é que os há - técnicos de administração estarão mais bem equipados pelo treinamento ocupacional do que os classificadores de cargos, para esquadrinhar e definir espécies de trabalho, niveis de responsabilidade e caracteristicas de cargos.

Equilibrio - es classificadores de cargos devem estabelecer atribuições que, reflitam a distribuição de respensabilidades definida pelos técnicos de organ1zação e métodos. Seu trabalho não é fácil, alterando aqui e ali, para conciliar modificações surgidas e situando a autoridade próxima aos pontos de ação, sem fracionar esta última, e perturbam-se quando os resultados de suas composições não refletem o que haviam inicialmente estabelecido. A disparidade é em geral explicada pela dificuldade dos classificadores em compreenderem o papel correspondente ao cargo que estão demarcandis, ou pela incapacidade dos supervisores e empregados de se adaptarem às modificações. Longas conferências são úteis. via de regra, para remover as disparidades, mas tais mal-entendidos não ocorreriam se o classificador participasse do trabalho de definição das responsabilidades e e se o organizador acompanhasse, depois, o contrôle da execução.

Divisão do trabalho - a definição de diferentes espécies de trabalho é fundamental para ambos os especialistas. Os técnicos de organização estudam e definem a natureza e o número de funções básicas existentes numa unidade de trabalho. Os classificadores dão nome a essas funções e as arrumam em posição, na proporção em que as mesmas vão sendo atribuidas a correspondentes cargos. Não há negar que cssas tarefas diferem entre si, mas são tão diferentes os conhecimentos necessários para sua execução? Se os dois especialistas são competentes, disporão de um conhecimento sôbre a 
orgnnização que não será excedido por ninguém, dentro do grupo administrativo. Cada um deve ser capaz de distinguir entre grandes e pequenas fuições e antre importantes e não importantes tarefas. Cada um deve saber reconhecer e justificar a influência dos fatôres de personaliłade na estrutura da organização. Se afastarmos êsses processos de trabalho e êsses requisitos de cuilıecimento, pouco restará em qualquer dos campos.

Definição de funções e conteúdo do trabalho Quase todo classificador reclama contra a má organização e a soma de mal definida, responsabilidade de que toma conhecimento no decorrer de suas investigaçóes. O trabalho combinado que sugerimos aqui dar-lhe-á oportunidade de desempenhar com o máximo de rendimento sua função de "serviço", do mesmo modo o hiabilitará a dar cumprimento à lei. Que acontecerá, entäo, em semelhante esquema, à tôrre de marfim em que se encastelou a classificação de cargos e sôbre a qual tanto ouvimos falar? Creio que se desvanecerá, junto com muitos dos males da excessiva especialização.

Os técnicos de organização e métod'ss de trabalho também se vêem, às vêzes, numa espécie de tôrre de marfim. Se tomaren parte no processo de classificação. colherão uma série de vantagens, pela ampla oportunidade que terão de ver, no nascedouro, os efeitos de suas recomendações, coisa que raramente podem ver com a perspectiva indispensável daquele que procede à classificação individual de cargos.

Ainda um outro aparte ao tema "o maior dos serviços à administração". e que é o seguinte: muitos órgäos regionais do govêrno federal poderiam conduzir melhor seus interêsses se dispusessem de maior autoridade em matéria de organização e classíficação. A combinação das duas funções em cargos únicos tornaria mais econômico para as repartições a delegação de tais atribuições a niveis mais baixos da organização.

Acredita-se que os classificadores executam seu trabalho de definição de atribuições na base daquilo que apuram no desempenho das tarefas, embora em razão de fatôres de personalidade ou outros motivos, os cargos acabem diferindo do que figurava no plano inicial de organização. Uma das críticas feitas à com. binação aqui proposta assinala que, se o mesmo técnico que prerề um cargo num plano de classificação também executa o trabalho de classificá-lo, poderá prevalecer uma forte tendência 
para classificar antes de acôrdo com o plano do que em função da situação real em que o trabalho é executado. A minha resposta é que um técnico realmente competente perceberá o valor de situações "não autorizadas", mas que tenham mérito - mérito êsse que decorrerá das pessoas que estejam preenchendo os cargos, ou de defeitos inerentes ao plano de classificação. E èsse especialista estará, igualmente, em posição de decidir sôbre as situaçôes "não autorizadas" que não tenham valor aļ̧um. Os técnicos de administração, de modo geral, já se inclinam por dever de ofício a chamar a atenção para os casos de má utilização de mão-de-cbra e outras falhas de organização. O Programa de Utilização e Conservação de Mão-de-Obra, esposado pelo Presidente da República, torna isso bem claro. Não obstante, essa responsabilidade não elimina os problemas de coordenação decorrentes de um excesso de especialização.

A sugestão contida neste trabalho limita-se, apenas, às tarefas cotidianas nos dois campos, porque é muito possível que a concentração dos encargos de classificação em postos individuais venha a ser uma desvantagem nos altos escalões. de planejamento da organização, onde decisões de grande importância, comı por exemplo a determinação de funções substantivas de vastas divisöes, dãc a medida do trabalho. Isso não deveria, porém, constituir uma grande limitação, já que a proporção maior do trabalho de classificação e organização no Serviço Público não tem êsse caráter, consistindo apenas em problemas diários de manutenção. A proposta não visa, também, à aplicação aos classificadores da Comissão do Serviço Civil, cuja autoridade decorre mais de preceitos estatutários do que de critério administrativo.

Em resumo, a divisão de trabalho que ora prevalece, separando tarefas cotidianas de organização e classificação, representa um desperdício, em têrmos de duplicação e mal-entendido, além de ser antinatural, em têrmos de princípio e de método. Para cada um dêsses campos, recrutamos principiantes portadores das mesmas qualificações fundamentais, tornamo-los familiares com os mesmos princípios, ensinamos-lhes as mesmas técnicas. Depois disso tudo, passamos a classificá-los em diferentes grupos ocupacionais, colocamo-los em diferentes locais de trabalho e dedicamos enormes esforços à tentativa de manter os dois grupos em harmonia. Alguns anos dêsses esforços não serviram para eliminar. nem mesmo para reduzir de forma significativa os problemas de coordenação. Classificação e organização, na realidade, constituem um campo só. Por que não as combinar?

In Personniel Administration ("Administração de Pessoal"), vol. 16, n 3, maio de 1963. 